\title{
The Structure of Cast Irons
}

\author{
John Campbell \\ Emeritus Professor of Casting Technology, Department of Metallurgy and Materials, \\ School of Engineering, University of Birmingham, UK \\ jc@campbelltech.co.uk
}

Keywords: cast irons, ductile iron, oxide film, bifilm.

\begin{abstract}
There appear to be two main growth mechanisms for graphite in cast iron:
i) Coupled eutectic growth forms of gray irons which are classical growth modes of simultaneous parallel growth of graphite and austenite, not reliant on a bifilm mechanism. These are necessarily fine structures as a result of their control by the rate of diffusion of carbon in the liquid. These structures are well understood.

(ii) Uncoupled eutectic mechanisms which appear to be much less well understood, including (a) growth of graphite on silica bifilm substrates floating freely in the melt, forming such structures as A-type graphite flakes. This prediction appears to have now been confirmed by direct observation. The transition to (b) nodular morphology occurs by $\mathrm{Mg}$ eliminating the silica bifilms by an exchange reaction. In this way the substrates for flake growth are instantly removed, and graphite can now wrap completely around nuclei, thereby growing as a nodule.

Graphite structures in heavy sections such as chunky graphite may now be understandable in terms of the reorganisation by flotation of bifilms and/or nuclei.
\end{abstract}

\section{Introduction}

Bifilms are those defects in liquid metals which result from the turbulence of stirring and pouring, in which the surface oxide film becomes entrained in the melt. The entrainment mechanism ensures that the submergence of the surface film necessarily occurs with the upper dry surface of the film contacting an opposed upper dry surface, thereby forming a double film with no bonding between the two films. For this reason the bifilm acts as a crack in the liquid. Very turbulent pouring can fill the liquid with cracks.

Practically all metals (with a few interesting exceptions) are dominated by their populations of bifilms, floating, in suspension in the liquid metal prior to solidification. Cast iron appears to be no exception. However, cast iron appears to be unusually complex, with bifilms of several different compositions depending on conditions. The structure and the properties of irons appear to be greatly influenced by the number, size and composition of the bifilms they contain. This short paper is a brief overview.

\section{Films in Cast Irons}

Graphite (lustrous carbon) films on cast irons are widely experienced. They result from the breakdown of hydrocarbons on the surface of the liquid metal, allowing hydrogen to diffuse away, but leaving carbon as a strong film on the liquid surface. This film is easily folded into the metal, creating known graphitic bifilm defects. Interestingly, and unusually for bifilms, in heavy sections they have the time to dissolve and disappear [1].

A quite different, silica $\left(\mathrm{SiO}_{2}\right)$, film covering liquid gray irons between approximately 1300 and $1400 \mathrm{C}$ can be seen with the unaided eye. Above this range the iron is clear of any film, but below, the contributions of $\mathrm{FeO}$ and $\mathrm{MnO}$ lower the $\mathrm{mp}$, so that the oxide film is liquid. The temperature dependence of the film on liquid gray irons gives rise to its complex behavior [1].

The question of the stability of silica in the liquid is interesting. Clearly, silica is stable during the melting and holding of irons in the 1300 to $1400{ }^{\circ} \mathrm{C}$ temperature range. If entrained into the bulk of the liquid by surface turbulence at this temperature, the bifilms formed in this way will be able to 
survive in suspension indefinitely. However, during pouring, as the temperature falls below $1300 \mathrm{C}$ they will start to dissolve. However, there is sufficiently little time between pouring and solidification so that they will survive sufficiently long to act as substrates for nucleation of nuclei, and the growth of graphite.

The silica film, when entrained into the bulk as a bifilm, first attracts the universal oxy-sulphide nuclei to nucleate on it (these nuclei seem to be instrumental in nucleating both flake and nodular irons [2]). The carbon in solution then nucleates as graphite on this particle. Further growth of the graphite occurs as its spreads out on the planar substrate provided by the silica. If it grows on both sides of the silica bifilm then the apparently single flake will have a crack down its center. Most graphite flakes are expected to be of this form, explaining the poor mechanical properties of flake irons. (Although graphite has the well-known low shear strength, its tensile strength in the $<0001>$ direction is not negligible at $600 \mathrm{MPa}$ [3], so that without the presence of bifilms in the flakes, gray irons would have quite moderate strengths and ductility).

It is with amazing good fortune that the surface oxide on liquid gray iron starts to become liquid below $1300 \mathrm{C}$ as iron and manganese start to oxidise preferentially to form iron and manganese silicates as surface films. This complex behavior ensures that the bulk of iron, cooling during pouring from normal casting temperatures, contains unstable and shrinking, but surviving, silica bifilms in its interior, but stable liquid oxides on its exterior surface. This is an amazing combination of benefits: the interior silica bifilms are the growth substrates for type ' $\mathrm{A}$ ' graphite, and the exterior liquid film ensures that no damaging bifilms can be formed during pouring. The liquid-coated liquid metal surface creates the metal's insensitivity to casting turbulence, thereby conferring the excellent castability of gray irons. The liquid oxide-to-liquid oxide impingement of the surfaces of droplets and splashes cannot result in the formation of a bifilm crack defect, which is why the industrial revolution was successful!

In passing, it is worth emphasizing that this behavior of grey iron during pouring is in contrast to most liquid metals which have solid oxide films. Impingement of splashes during careless handling of most liquid metals results in solid oxide-to-solid oxide contact, creating double oxide films (bifilms) which cannot bond and which therefore act as cracks. The same handling of grey iron liquid, with its liquid surface oxide film, gives a metal of no major entrained cracks (even though the millions of sub-millimetre sized silica bifilms, as cracks, continue to form the substrates for graphite flakes.)

Loss of the population of silica bifilms in suspension seems to be possible both above 1500 and below $1300{ }^{\circ} \mathrm{C}$, so that a very poor uninoculated structures would be expected after sufficient time in both temperature regimes.

For instance, it is well known that this can occur if an induction furnace is held at a sufficient temperature for only 20 minutes, and certainly over a weekend. It does not seem to be known whether the loss of oxy-sulfide nuclei or loss of silica substrates for growth. What is certain is that simple inspection of the surface of the liquid gray iron at $1550{ }^{\circ} \mathrm{C}$ confirms an absence of any surface film, confirming that silica is not stable at this temperature. All silica bifilms in suspension will therefore go into solution. During pouring, as parts of the metal stream oxidize and cool, some silica will form. If nuclei are also present this would allow the formation of some graphite flakes. However, the silica in suspension would, in general, be insufficient to provide a good population of substrates for graphite growth. The few flakes that would form would grow oversize, but most carbon would be unable to precipitate, and would therefore nucleate much later during cooling to form carbides.

We should also recall that it also seems risky to hold liquid iron at temperatures below $1300{ }^{\circ} \mathrm{C}$ if good inoculation is required, since, once again, the silica substrates for graphite will be unstable and gradually disappear. The author is not sure whether the danger of this low temperature regime is widely known, or whether this is a prediction yet to be tested. 


\section{Alloy Irons}

Other varieties of oxides are to be expected on other liquid alloy irons, such as alumina $\left(\mathrm{Al}_{2} \mathrm{O}_{3}\right)$ on aluminum cast irons, chromia $\left(\mathrm{Cr}_{2} \mathrm{O}_{3}\right)$ on high chromium alloys, and liquid borates on white irons containing boron.

High Al cast irons can be expected to contain a population not of silica but of alumina bifilms. As such, it will be more difficult to reduce these by addition of $\mathrm{Mg}$, therefore requiring stronger deoxidizers such as $\mathrm{Ca}$ to convert the flake graphite to nodular. In the case of boron cast irons, the surface film on the iron will be an iron borate, with a melting point probably below $1000{ }^{\circ} \mathrm{C}$. This liquid film, when entrained, will merely mutually assimilate and coalesce into droplets, so that solid oxide substrates for graphite cannot form. The action of boron therefore is to completely eliminate graphite as flakes, converting the iron to white, carbidic iron. This action is so effective that boron should be avoided as an alloying element for cast iron on environmental grounds; although trace levels of boron are occasionally used as an alloying element in irons, if accidentally introduced at higher levels, boron's ability to stabilise white iron could destroy a day's production in a foundry.

\section{Ductile Irons}

The addition of $\mathrm{Mg}$ to gray iron immediately destroys the silica ( $\mathrm{SiO} 2)$ films, releasing $\mathrm{Si}$ into the melt and tying up the oxygen as $\mathrm{MgO}$ [1]. Interestingly, it is not clear what happens to this residual $\mathrm{MgO}$. It may contribute to the oxy-sulfide particles already in the melt which constitute the favored nucleation sites for spheroidal graphite (in the same way that the population of oxy-sulfides formed the nucleation sites for flakes, having themselves first nucleated on the silica bifilms). The dramatic action of $\mathrm{Mg}$ to destroy the favored substrates for flakes explains the magically abrupt action of $\mathrm{Mg}$ to convert flake iron to nodular iron.

It is the absence of silica bifilms which explains the good ductility of ductile iron, whereas the sphericity of the graphite nodules, although often assumed to be of central importance, is probably a negligible contribution to ductility.

For instance, poor nodularity is associated with loss of properties not because of the loss of sphericity of nodules but because of the presence of bifilms introduced by a turbulent filling system. Unfortunately nodular iron is degraded by uncontrolled and turbulent filling (in contrast to gray iron) because of the solid MgO-rich film on the surface of the liquid metal which creates effective Mg-rich bifilm cracks. The bifilms are probably composed of magnesium silicate $\left(\mathrm{MgSiO}_{3}\right)$. The bifilms which affect nodularity are usually invisibly thin, and only detected by their role as preferred substrates for graphite, thereby encouraging the graphite to grow in contact with the planar bifilms, threatening nodularity and threatening properties.

There is now good experimental evidence for the linking of turbulence and bifilm creation with loss of tensile properties and fatigue performance in ductile irons $[4,5]$.

\section{Classical Coupled Eutectic Growth}

The formation of graphite on nuclei wandering about in the liquid [2], forming either flake or nodular irons, are examples of a non-coupled growth form; the new phases as individual particles initiate and grow independently of each other.

In the case of coupled growth, bifilms have no role. Growth initiates from a single nucleation event, and both phases grow together, each assisting to control the rate of growth and the spacing of the other phase by diffusion through the liquid ahead of their cooperatively advancing front. These are the types of eutectic famously explained for the first time in 1966 by Hunt and Jackson [6]. A number of iron/graphite structures fall into this category. Cellular and/or rosette growth takes this form; each cell being nucleated from a single nucleus; the outward spreading is a coupled growth of austenite and graphite. The fine spacings of types D and E graphite are examples of coupled growth usually on a much larger front (a nucleation event having been left a long way behind). Coral graphite, compacted graphite and chunky graphite all seem to be more-or-less cooperative growth forms. 
Readers need to be aware that mixed structures in irons are common. One often sees large type A flakes which have formed on silica bifilms floating about freely in the melt which have later become overtaken and entrapped in a coupled growth of some variety of finely-spaced eutectic iron which has grown on a wide planar front. This effect is clearly seen in a number of the microstructures of the ASTM A247 wall chart published by the AFS Cast Iron Division. It seems probable that mixed populations of graphite forms will be unhelpful when optimizing properties. An understanding of the different modes of formation of flakes would allow improved control, and probably improved properties. This remains a future challenge.

\section{Other Film Defects in Irons}

Bubble trails are the visible evidence of the different varieties of films common in cast irons. In the case of core blows which have been studied in a gray iron casting [1,7], the initial volatiles from the core will be water vapor. Water vapor is highly oxidizing, creating silicate films around the jets of vapor through the liquid metal. As the core absorbs more heat, and the moisture is all driven off, the hydrocarbons then start to boil off. The jets of hydrocarbon vapour then create carbon films. If the jets become especially vigorous, the earlier silica films become scrambled by the energetic turbulence to form tangled bundles of slag (usually misidentified as originating from the ladle; it is worth noting that slag defects in castings are rarely from the ladle; most slag defects in iron castings actually originate in the turbulence of the running system. The masses of slag are actually masses of bifilms.).

\section{Conclusions}

1. As in most metals, both surface films and internal bifilms are common in cast irons.

2. Core blows demonstrate the production of both oxide and carbonaceous films.

3. Flake graphite in gray iron nucleates on oxy-sulfides but grows on silica bifilm substrates, the central bifilm crack explaining the low strength and brittleness of grey iron.

4. Graphite nodules in ductile iron nucleate and grow around oxy-sulfide particles. The ductility of ductile iron is the result of the elimination of the bifilm substrates by Mg. Loss of ductility in ductile iron is the result of the re-introduction of Mg-rich bifilms by poor metal handling.

5. The numerous varieties of coupled growth of graphite and austenite (cellular, E-type, F-type, coral, compacted, chunky graphite) have nothing to do with bifilms; their spacing is dictated by classical considerations of surface energy and diffusion in the liquid.

6. Most iron castings contain mixed populations of graphite forms, due to both bifilm and coupled growth mechanisms. Such mixtures will generally be unhelpful in the optimization of properties. Controlled, single populations will be required for future optimized irons.

\section{References}

[1] J Campbell, Complete Casting Handbook, $2^{\text {nd }}$ Edition, Elsevier, Oxford, UK, 2015.

[2] I. Riposan, M. Chisamera, S. Stan, P. Toboc, E. Ecob, D. White, Al, Zr-FeSi preconditioning of grey cast irons, Mater Sci Tech 24 (5) (2008), 579-584.

[3] S. Okamoto, Ehime University, Matsuyama, Japan; personal communication 2013.

[4] J. Campbell; Fatigue Fracture of Cast Irons; Int J Metalcast 2 (No. 2) (2008), 43-46.

[5] F-Y. Hsu, K-N. Wang, C-L. Li, Bifilm defects in ductile iron support bracket castings, Int J Cast Metal Res 30 (3) (2017), 148-158.

[6]J. D. Hunt, K. A. Jackson, Trans Metall Soc AIME 236 (1966), 843-852 and 1129-1142.

[7]J. Campbell, R. L. Naro, Lustrous carbon in grey iron, AFS Trans, 114 (2010), 10-36. 